\title{
Análise do comportamento de um solo na presença do esgoto doméstico em vala de Infiltração
}

A fonte de contaminação oriunda do esgoto domésticos para o solo e consequentemente para as águas subterrâneas é uma realidade atual. No Brasil, o sistema de tratamento primário do esgoto através de tanque sépticos com filtro anaeróbio e vala de infiltração atende uma grande parcela da população brasileira, conforme Relatório (ABES, 2015). Para tanto, realizou-se uma Sondagem a Percussão em 4 pontos determinados e 5 furos na área da vala de infiltração em profundidades de 0,50 metro e 1,00 metro. Foram realizados ensaios de permeabilidade in loco avaliando o valor da condutividade hidráulica, valores de granulometria, Índices de Plasticidade, Limites de Liquidez, Limites de Plasticidades, Demanda bioquímica de oxigênio, Demanda química de oxigênio, Concentração de Nitrato, concentração de Nitrito, amônia, coliforme totais e termotolerante e estimação ao longo do tempo do alcance da pluma contaminante do esgoto doméstico tratado no subsolo. A partir dos resultados obtidos, conclui-se que os parâmetros e estudos realizados se constate que a carga de contaminação oriunda da amostra do Esgoto doméstico não atingem o nível do lençol freático, não gerando a propagação da contaminação. A utilização da própria vegetação com seu sistema radicular contribui para decrescer os níveis de Nitratos e Nitritos a patamares aceitáveis, de acordo com a Resolução do Conama 357 (BRASIL, 2005 ) e a matriz PEIR demostra que existe a possibilidade do Impacto ambiental alto, mas as respostas do sistema demostram que as características do meio mitigam está possível contaminação

Palavras-chave: Nitratos/Nitritos; Permeabilidade; Meio ambiente e PEIR.

\section{Analyze of the behavior of a soil in the presence of domestic sewage in Infiltration Ditch}

\begin{abstract}
The source of contamination from domestic sewage to the ground and consequently to groundwater is a current reality. In Brazil, the primary treatment system of the sewage through septic tank with anaerobic filter and infiltration ditch serves a large part of the Brazilian population, according to Report (ABES, 2015). For this purpose, a Percussion Drill was carried out at 4 determined points and 5 holes in the infiltration trench area at depths of 0.50 meters and 1.00 meters. In situ permeability tests were carried out, evaluating the hydraulic conductivity values, granulometry values, Plasticity Indexes, Liquidity Limits, Plasticity Limits, Biochemical Oxygen Demand, Chemical Oxygen Demand, Nitrate Concentration, Nitrite Concentration, Ammonia, total coliform and thermotolerant and estimation over time of the reach of the contaminating plume of treated domestic sewage in the basement. From the results obtained, it is concluded that the parameters and studies carried out show that the contamination load from the domestic Sewage sample does not reach the water table level and does not generate the contamination propagation. The use of the vegetation itself with its root system contributes to decreasing Nitrate and Nitrite levels at acceptable levels according to Conama Resolution 357 (BRASIL,2005) and the PEIR matrix demonstrates that there is a possibility of high Environmental Impact, but the responses of the demonstrate that the characteristics of the environment mitigate this possible contamination.
\end{abstract}

Keywords: Nitrates/Nitrites; Permeability; Environment and PEIR.

Topic: Engenharia da Sustentabilidade e Meio Ambiente

Reviewed anonymously in the process of blind peer

José Messias Ribeiro Júnior (ib)

Instituto de Tecnologia de Pernambuco, Brasil

http://lattes.cnpq.br/7986236521435988

http://orcid.org/0000-0002-7142-0948

messias engenharia@yahoo.com.br

Eduardo Antonio Maia Lins (iv)

Instituto Federal de Pernambuco, Brasil

http://lattes.cnpq.br/6148771863554184

http://orcid.org/0000-0002-9108-4179

eduardomaialin@gmail.com

Daniele de Castro Pessoa de Melo (it)

Instituto Federal de Pernambuco, Brasil

http://lattes.cnpq.br/4010783198064867

http://orcid.org/0000-0003-4058-092X

daniele.castro@itep.br

DOI: 10.6008/CBPC2179-6858.2019.003.0012
Received: 12/04/2019

Approved: 27/05/2019
Jeane Emili de Medeiros (ib

Instituto Federal de Pernambuco, Brasil http://lattes.cnpq.br/0831232189900372 http://orcid.org/0000-0001-6841-8161

jeane.medeiros@reitoria.ifpe.edu.br
Referencing this:

RIBEIRO JÚNIOR, J. M.; LINS, E. A. M.; MELO, D. C. P.; MEDEIROS, J. E. Análise do comportamento de um solo na presença do esgoto doméstico em vala de Infiltração. Revista Ibero Americana de Ciências Ambientais, v.10, n.3, p.124-137, 2019. DOI:

http://doi.org/10.6008/CBPC2179-6858.2019.003.0012 


\section{INTRODUÇÃO}

As edificações que não dispõem de rede pública coletora de esgotos necessitam adotar medidas para o tratamento e disposição dos efluentes. Os sistemas compostos por tanques sépticos interligados em valas de infiltração ou sumidouros representam uma solução possível para o problema, desde que o nível do lençol freático esteja numa profundidade onde não haja risco de contaminação (MARQUES et al., 2010). O líquido que percola dos Tanques sépticos para o solo contem nitrogênio (convertido em nitrato, no solo). Como consequência, a água subterrânea sob as, ou perto das, fossas pode se tornar poluída, o que causa problemas quando a qualidade da água de abastecimento, retirada de poços é afetada (SPERLING, 2014).

A situação de utilização do sistema primário de tratamento de esgoto se faz presente no Instituto Federal de Pernambuco, ou seja, não cabe somente atender as recomendações construtivas das agências estaduais de meio ambiente como a companhia Pernambucana de Recursos Hídricos (CPRH), pois os elementos inorgânicos (Nitratos/Nitritos) do Esgoto domésticos não são tratados por estes sistemas convencionais, e consequentemente são fontes de contaminação ao meio (VARNIER et al., 2017).

O nitrato é formado por uma reação sequencial catalisada por microrganismos, através da oxidação

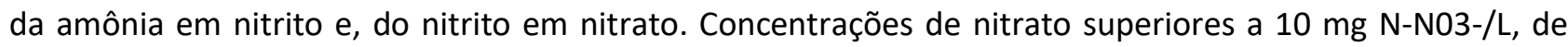
acordo com a organização Mundial da Saúde (OMS) e o Ministério da Saúde podem causar a metemoglobinemia, podendo trazer graves consequências para a saúde, inclusive morte, principalmente em lactentes.

Uma importante diretriz para análise dos parâmetros da qualidade da água é a Resolução no 357, de 17 de março de 2005 do Conselho Nacional do Meio Ambiente (CONAMA) que estabelece os parâmetros dos Contaminantes inorgânicos como o Nitrato e o Nitrito que é a abordado nesta pesquisa. Ressalta-se que Resolução $\mathrm{n}$ - 430 do CONAMA não abrange os contaminantes específicos citados, bem como a resolução $\mathrm{n}$ 420 propõe a análise físico-química de parâmetros de águas subterrâneas.

O solo atua como um filtro para os contaminantes. Mas quando sua capacidade amortecedora é superada, os contaminantes podem chegar ao meio ambiente e consequentemente causando danos a sociedade, sendo por isso, objeto de diversos estudos, segundo a Organização das Nações Unidas para a Alimentação e a Agricultura (FAO, 2018).

O presente estudo justifica-se pelo o grande número de unidades habitacionais cerca de 22.266.728, segundo Relatório de 2015 da Associação brasileira de Engenharia Sanitária e Ambiental (ABES, 2015) que utilizam o sistema de tratamento primário através de Taque sépticos com disposição final para o solo, ou seja, o monitoramento e estudo dos contaminantes (Nitratos $-\mathrm{NO}_{3}$ e Nitritos $-\mathrm{NO}_{2}$ ) é imprescindível para análise e atenuação da carga contaminante ao meio (QUAGGIO et al., 2018).

Dessa forma, o estudo objetivou Identificar e estimar o comportamento do transporte de contaminantes do esgoto sanitário, especificamente os Nitratos (NO3) e Nitritos (NO2), para o meio poroso, na área da vala de Infiltração do Instituto federal de Pernambuco-Campus Recife, avaliando o impacto ambiental através da matriz de PEIR. 


\section{MATERIAIS E MÉTODOS}

A presente pesquisa compreendem a análise do transportes de Contaminantes Nitratos (NO3) e Nitritos (NO2) do esgoto tratado destinados a uma vala de infiltração (Figura 1) da Edificação do centro de Pesquisa do IFPE-Campus Recife. Para este estudo seguiu-se metodologias tantos com estudos in loco como ensaios em laboratórios a fim de se obter parâmetros para análise do transportes destes fluídos no meio poroso.

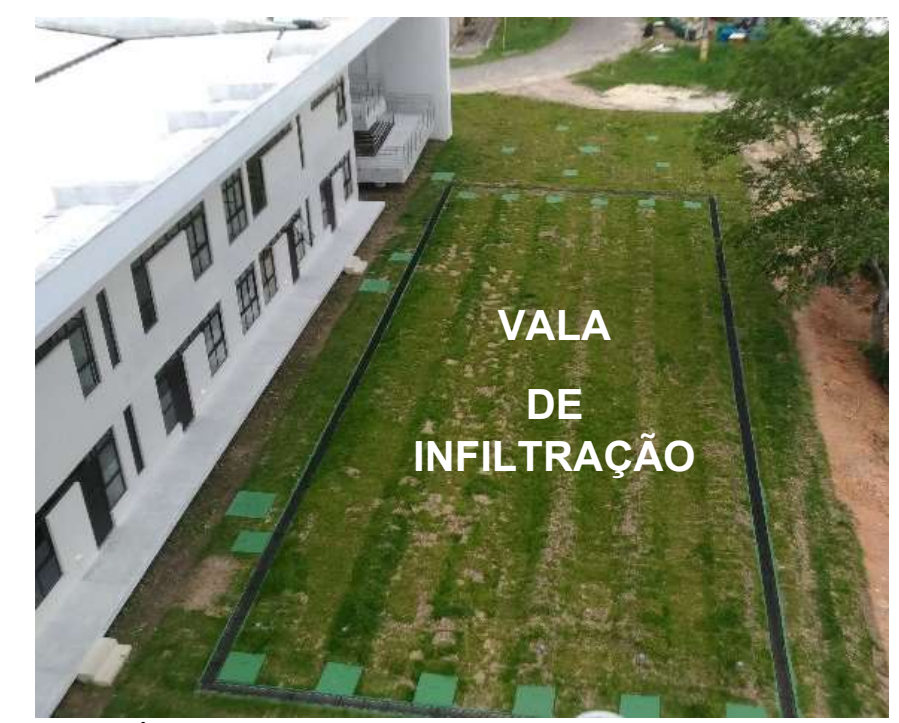

Figura 1: Área da Vala de Infiltração do Centro de Pesquisa - IFPE.

\section{Área de Estudo}

O estudo se fez na área da vala de infiltração da edificação do Centro de Pesquisa do IFPE (Figura 1), localizado na Av. Prof. Luiz Freire, 500, Cidade Universitária, Recife/PE com coordenadas geográficas de 803'34" sul e 345' $00^{\prime \prime}$ oeste. A edificação é composta de 2 pavimentos sendo um térreo e outro um 1응 andar, com uma área construída de $1553 \mathrm{~m}^{2}$, composta de 10 laboratórios multidisciplinares, 17 salas de pesquisadores, copa, almoxarifado, 4 (quatro) banheiros coletivos, 2 (dois) individuais e Recepção.

O Sistema de tratamento do esgoto adotado (Figura 3) é composto por tanque séptico, filtro anaeróbico e vala de infiltração com vazão de esgoto estimada de 10.000 litros por dia, conforme dados do projeto hidrossanitários. O nível do Lençol freático apresentou variação devido a influência do Clima As' da classificação de Kopper (tropical úmido), com chuvas concentradas (Tabela 1) no período de abril a Julho tendo um nível hidrostático de - 3,00 metros e no período de estação seca um nível de - 5,00 metros de profundidade. O perfil do solo da área de estudo se caracteriza por uma camada de 1,5 metro de aterro com predominância de solo Areia-Argila. E na camada subsequente o solo apresenta características arenosas, conforme ensaios de Sondagem a Percussão. 


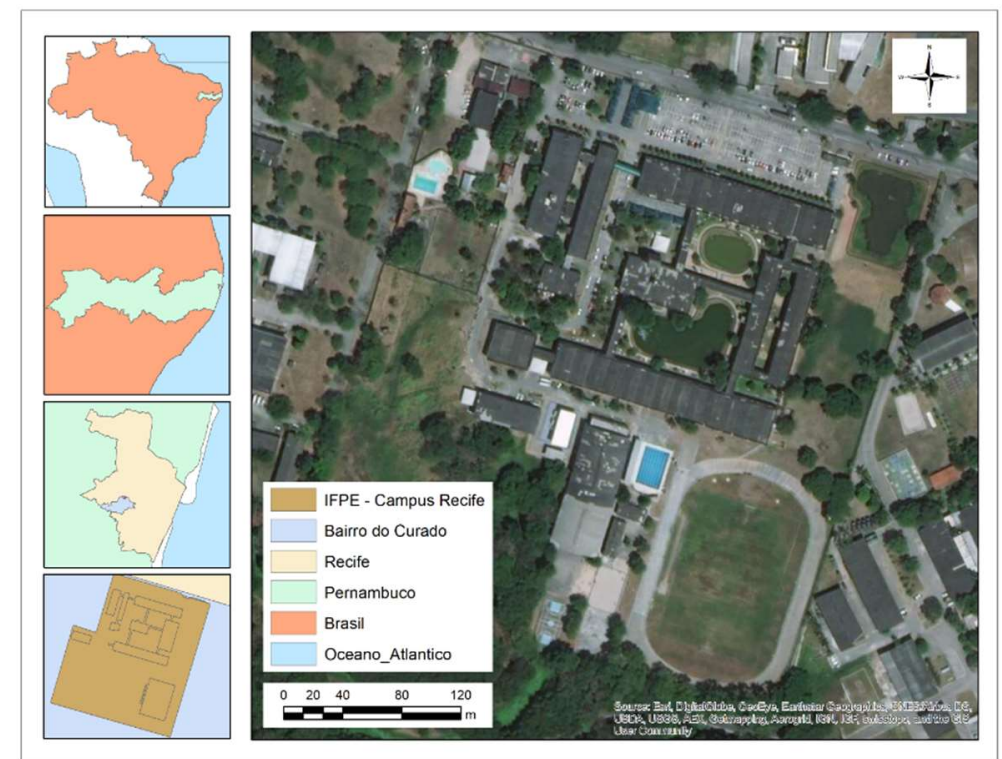

Figura 2: Mapa de Localização do Centro de Pesquisa.

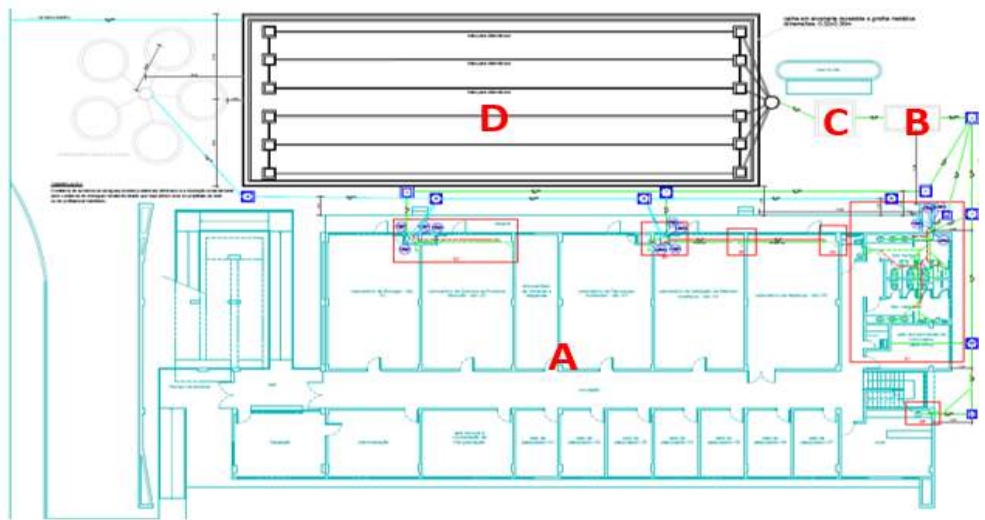

Figura 3: Planta baixa da edificação e do Sistema de Tratamento de Esgoto.

(A) - Edificação, (B) - Tanque Séptico, (C) - Filtro Anaeróbio e (D) - Vala de Infiltração.

Fonte: Departamento de Obras e Projetos de engenharia do IFPE (2017).

Tabela 1: Série histórica de 10 anos de Precipitação mensal na Região Metropolitana do Recife, Estação: 82900, Unidade em milímetro ( $\mathrm{mm}$ ).

\begin{tabular}{|l|l|l|l|l|l|l|l|l|l|l|l|l|}
\hline ANO & JAN & FEV & MAR & ABR & MAI & JUN & JUL & AGO & SET & OUT & NOV & DEZ \\
\hline $\mathbf{2 0 0 7}$ & 83,5 & 226,7 & 138,7 & $\mathbf{3 4 7 , 3}$ & $\mathbf{2 0 8 , 2}$ & $\mathbf{3 9 0 , 8}$ & $\mathbf{3 3 1}$ & 223,7 & 127,1 & 25,6 & 40 & 30,6 \\
\hline $\mathbf{2 0 0 8}$ & 85,7 & 32,3 & 395,4 & $\mathbf{3 1 4 , 2}$ & $\mathbf{4 1 5 , 7}$ & $\mathbf{3 9 1 , 8}$ & $\mathbf{3 7 4 , 3}$ & $\mathbf{2 9 4 , 4}$ & 47,6 & 53,6 & 16 & 18,3 \\
\hline $\mathbf{2 0 0 9}$ & 85,2 & 376,1 & 142,8 & $\mathbf{3 5 1 , 8}$ & $\mathbf{4 1 0 , 1}$ & $\mathbf{3 3 3}$ & $\mathbf{3 8 6 , 8}$ & $\mathbf{2 9 0 , 2}$ & 83,5 & 16,3 & 49,9 & 47,8 \\
\hline $\mathbf{2 0 1 0}$ & 193,4 & 45,2 & 92,7 & $\mathbf{2 7 3 , 3}$ & $\mathbf{1 1 4 , 3}$ & $\mathbf{5 4 3 , 9}$ & $\mathbf{2 5 9 , 4}$ & 191,2 & 74,3 & 37,4 & 23,5 & 84,8 \\
\hline $\mathbf{2 0 1 1}$ & 139,3 & 336,6 & 129,5 & $\mathbf{6 4 7 , 4}$ & $\mathbf{7 5 5 , 7}$ & $\mathbf{3 0 3 , 9}$ & $\mathbf{5 4 4 , 4}$ & 201,8 & 35,7 & 34,6 & 75 & 41,8 \\
\hline $\mathbf{2 0 1 2}$ & 198,6 & 189,8 & 138,8 & $\mathbf{5 5 , 8}$ & $\mathbf{1 9 0 , 2}$ & $\mathbf{2 9 6 , 5}$ & $\mathbf{2 6 1 , 7}$ & 163,5 & 19,7 & 54,4 & 9,9 & 25,1 \\
\hline $\mathbf{2 0 1 3}$ & 95,7 & 47,7 & 98,8 & $\mathbf{2 2 9}$ & $\mathbf{3 1 6 , 9}$ & $\mathbf{4 9 1 , 4}$ & $\mathbf{4 1 6 , 4}$ & $\mathbf{2 2 5 , 3}$ & 146 & 129,2 & $\mathbf{7 6 , 5}$ & 177,3 \\
\hline $\mathbf{2 0 1 4}$ & 108,9 & 148,2 & 252,4 & $\mathbf{2 6 8 , 5}$ & $\mathbf{3 1 5 , 1}$ & $\mathbf{3 2 2 , 8}$ & $\mathbf{2 7 8 , 9}$ & 162,2 & 248,9 & 146,5 & 56 & 71,3 \\
\hline $\mathbf{2 0 1 5}$ & 65,4 & 56,2 & 341,2 & $\mathbf{7 4 , 6}$ & $\mathbf{1 7 8 , 9}$ & $\mathbf{4 6 0 , 5}$ & $\mathbf{4 4 6 , 3}$ & 116 & 35,1 & 16,6 & 30,6 & 91,8 \\
\hline $\mathbf{2 0 1 6}$ & 124 & 70 & 265,1 & $\mathbf{2 9 3 , 6}$ & $\mathbf{4 7 8 , 3}$ & $\mathbf{1 4 8 , 5}$ & $\mathbf{1 1 1 , 3}$ & 58,3 & 58,2 & 14,1 & 17,8 & 68 \\
\hline $\mathbf{2 0 1 7}$ & 28,7 & 21,1 & 156,2 & $\mathbf{2 8 9 , 7}$ & $\mathbf{3 9 7 , 6}$ & $\mathbf{4 8 9}$ & $\mathbf{4 8 6 , 5}$ & 112,1 & 83,8 & 62,6 & - & - \\
\hline
\end{tabular}

Fonte: INMET (2017).

\section{Ensaios de Campo e em Laboratório (Instrumentação)}

O estudo abordou um modelo quantitativo (LAKATOS et al., 2018) no qual realizou-se a instrumentação in loco com levantamentos topográficos da área de estudos com o instrumento Estação Total modelo TOPCON gpt 7500, a fim de definir a seção da vala de infiltração do Esgoto com suas dimensões (área $-\mathrm{m}^{2}$ ) e profundidades ( $\mathrm{h}-$ metro). 
As investigações de solos se fez com Sondagem a Percussão - SPT (standard penetration test) conforme preconiza a Norma ABNT NBR 6484/1997 em 4 (quatros) pontos determinados no terreno e as amostras deformadas do solo foram obtidas a partir de 5 (cinco) furos, na área da vala de infiltração (Figura 4), com o auxílio de um trado tipo cravadeira com DN= $150 \mathrm{~mm}$ para estudos geotécnicos das camadas de solos, em profundidades de 0,50 metro e 1,00 metro, totalizando a retirada de 10 (dez) amostras deformadas do solo para posterior envio ao laboratório de Geotecnia.

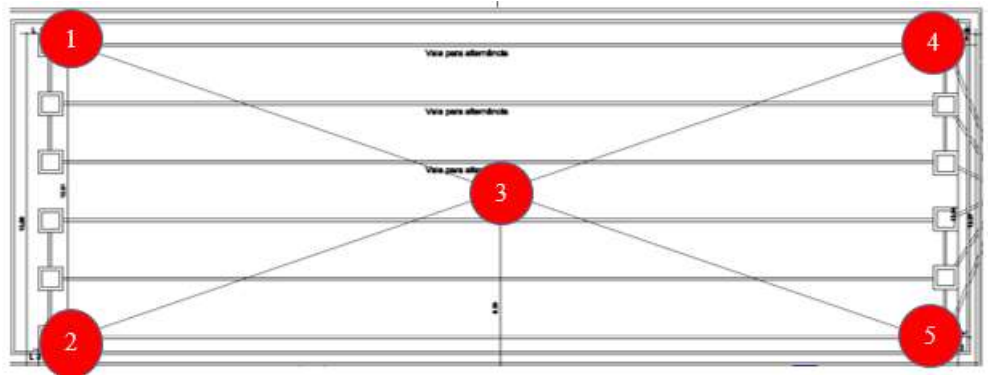

Figura 4: Locação dos Furos de Sondagem a trado na área da vala de infiltração.

Os Ensaios de permeabilidade realizado in loco, na área da vala de Infiltração do Centro de pesquisa, com permeâmetro de carga variável fabricado de acordo com o manual sobre permeabilidade da associação Brasileira de Geologia de Engenharia e Ambiental (ABGE, 2013), os fluídos ensaiados para determinação do K (coeficiente de Permeabilidade) foram água $\left(\mathrm{H}_{2} \mathrm{O}\right)$ e o percolado (Esgoto tratado) oriundo do próprio sistema de tratamento do IFPE-Recife como também preconizou o número de ensaio pela NBR 13969/1997 (ensaio de infiltração): a) Deve ser no mínimo 3 pontos, distribuídos a cobrir a maior área do local em estudo; b) Utilizar o Trado com DN $150 \mathrm{~mm}$ para escavar as cravas verticais.

Logo, foram realizados 6 (seis) ensaios de permeabilidade in loco 3 (três) com (H2O) e 3 (três) com Esgoto tratado, atendendo as recomendações da Norma citada. No ensaio de carga variável, o valor da condutividade hidráulica, K, é calculado segundo a equação 1, conforme Manual de "Ensaios de permeabilidade em solos - Orientações para sua execução em campo" (ABGE, 2013):

$$
\mathrm{K}=\frac{\Delta h}{\Delta t} \times \frac{D 1^{2}}{8 \times h 0 \times \sqrt{(D \times L)}}
$$

Equação: 1

Donde:

$\Delta \mathrm{h}$ é a variação das leituras de carga hidráulica no intervalo de

D1 é o diâmetro do permeâmetros

tempo $\Delta \mathrm{t}$;

$D$ é o diâmetro do furo de sondagem;

L é o comprimento do trecho de ensaio;

h0 é a altura entre o ponto de leitura no tempo $t=0$ e

Ponto médio do trecho ensaiado $(\Delta \mathrm{h}+$ profundidade do como ilustrado na Figura 05.

revestimento abaixo do solo $+\mathrm{L} / 2$ ), 


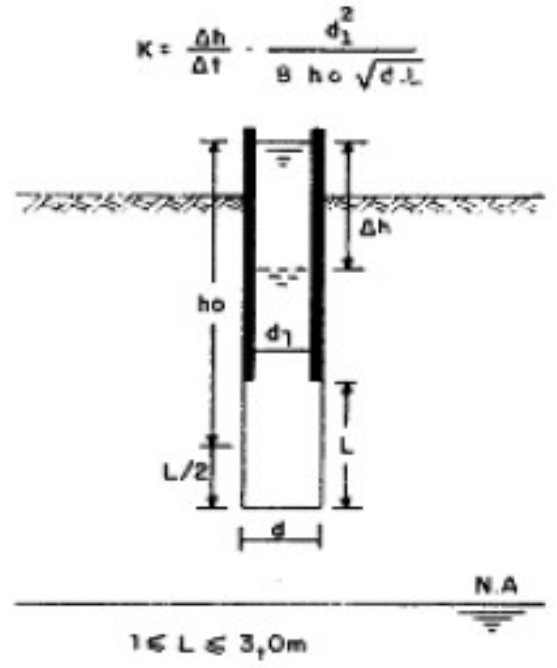

Figura 5: Ensaio de Infiltração a nível variável. Fonte: ABGE (2013).

As atividades de laboratórios, no caso, das amostras dos solos foram enviadas ao departamento de Geotecnia da Universidade Federal de Pernambuco-UFPE. A priori foi realizado a caracterização física do Solo em estudo de acordo com a NBR-ABNT 7181:2016 (Solo - Análise granulométrica) a fim de determinar os percentuais granulométrico de cada tipologia do solo e posteriormente utilizou-se a classificação do solo pelo sistema unificado de classificação do solo (SUCS). Os resultados das análises dos solos obteve-se a granulometria de cada tipo de solo, Índices de Plasticidade, Limites de Liquidez, limites de Plasticidades e outros.

Para os ensaios de esgoto tratado foram realizados 7 parâmetros: a Demanda bioquímica de oxigênio (DBO), Demanda química de oxigênio (DQO), concentração de Nitrato $\left(\mathrm{NO}_{3}\right)$, concentração de Nitrito $\left(\mathrm{NO}_{2}\right)$, amônia $\left(\mathrm{NH}_{3}\right)$, coliforme totais e termotolerantes, de acordo com os parâmetros nacionais da resolução do Conama no 357/2005. A amostra unitária Piloto (testemunha) de esgoto tratado retirada para análise é oriunda de uma caixa de distribuição do prédio do IFPE campus Recife que passou por um tratamento de Tanque séptico e tem destino para uma vala de infiltração com operação há cerca de 30 anos, com localização precisa dos pontos de coleta através de coordenadas Universal Transversa de Mercator (UTM) com receptor de navegação GPS (Global Positioning System - Sistema de Posicionamento Global). Os métodos de amostragem e preservação das amostras de esgoto seguiram os procedimentos adotados pelo Standard Methods e encaminhados ao Laboratório de análises químicas, microbiológica e ambiental do Instituto de Tecnologia de Pernambuco (ITEP). O cálculo da velocidade média de percolação do contaminante é obtido dividindo a velocidade de Darcy pela porosidade efetiva (n) através da Equação 2. A equação 3: $n$ (Porosidade efetiva), calculado pela equação de Van Beers (1965).

$$
\mathrm{V}=\mathrm{K} \times \mathrm{i} / \mathrm{n} \quad \text { Equação: } 2
$$




$$
\mathrm{n}=\mathrm{vkd} \quad \text { Equação: } 3
$$

Após determinar a velocidade linear média do Fluído contaminante pode-se estimar ao longo do tempo (anos) o alcance da pluma contaminante do esgoto doméstico tratado no subsolo, verificando-se a possibilidade de atingir o nível do lençol freático e propor medidas de atenuação dos impactos. Para obter um diagnóstico dos impactos ambientais é preciso ter uma visão holística na análise dos dados (MOURA et al., 2015), então foi aplicada a Matriz-PEIR para identificação e análise dos impactos negativos que poderão ser gerados e suas consequências para o meio ambiente.

\section{RESULTADOS E DISCUSSÃO}

\section{Sondagem a Percussão e a Trado (Caracterização geotécnica)}

A Sondagem a percussão seguiu os procedimentos da NBR 6484/1997 e a sondagem a trado tipo cravadeira seguiu as orientações da NBR 9603:2015. Na sondagem percussão, os relatórios apresentam uma classificação do material variando de uma areia fina, média e grossa, ressalta-se ainda que a camada de aterro (Areia-Argila) do Terreno ficou na média em torno de 1,50 metro com cota positiva em relação a cota 0,00 (Quadro 1) dos ensaios de sondagem a Percussão.

Quadro 1: Perfil adaptado e simplificado das camadas do Solo.

\begin{tabular}{|c|c|c|c|}
\hline Camadas (metro) & Perfil & Classificação do material & Descrição \\
\hline 1,5 & & \multirow{3}{*}{ AREIA-ARGILA } & \multirow{3}{*}{ ATERRO } \\
\hline 1 & & & \\
\hline 0,5 & & & \\
\hline 0 & & \multirow{6}{*}{ AREIA ( FINA, MÉDIA A GROSSA) } & \multirow{6}{*}{$\begin{array}{l}\text { TERRENO } \\
\text { NATURAL }\end{array}$} \\
\hline-1 & & & \\
\hline-2 & & & \\
\hline-3 & & & \\
\hline$(-3 a-24):$ & & & \\
\hline Limite da Sondagem & & & \\
\hline
\end{tabular}

Com a sondagem a trado na área da vala de infiltração foram retirados nos 5 furos as amostras de solos deformadas há profundidades de 0,50 m e 1,00 metro a fim de realizar a caracterização geotécnica do solo. Com as sondagem a Percussão e trado foi elaborado um perfil esquemático do solo da área de estudo com a tipologia de cada solo e suas profundidades bem como a identificação da variação do lençol freático (Figura 6) no período seco (N.A01) e no período chuvoso ( N.A 02).

Os ensaios de granulometria e sedimentação, permitiu obter os percentuais de cada tipo de partículas presentes no solo. As 10 amostras do solo demostrou a presença de um solo bem graduado, conforme os estudos de Freitas et al. (2017). Na Tabela 2 verifica-se os percentuais das frações granulométricas das amostras analisadas. 


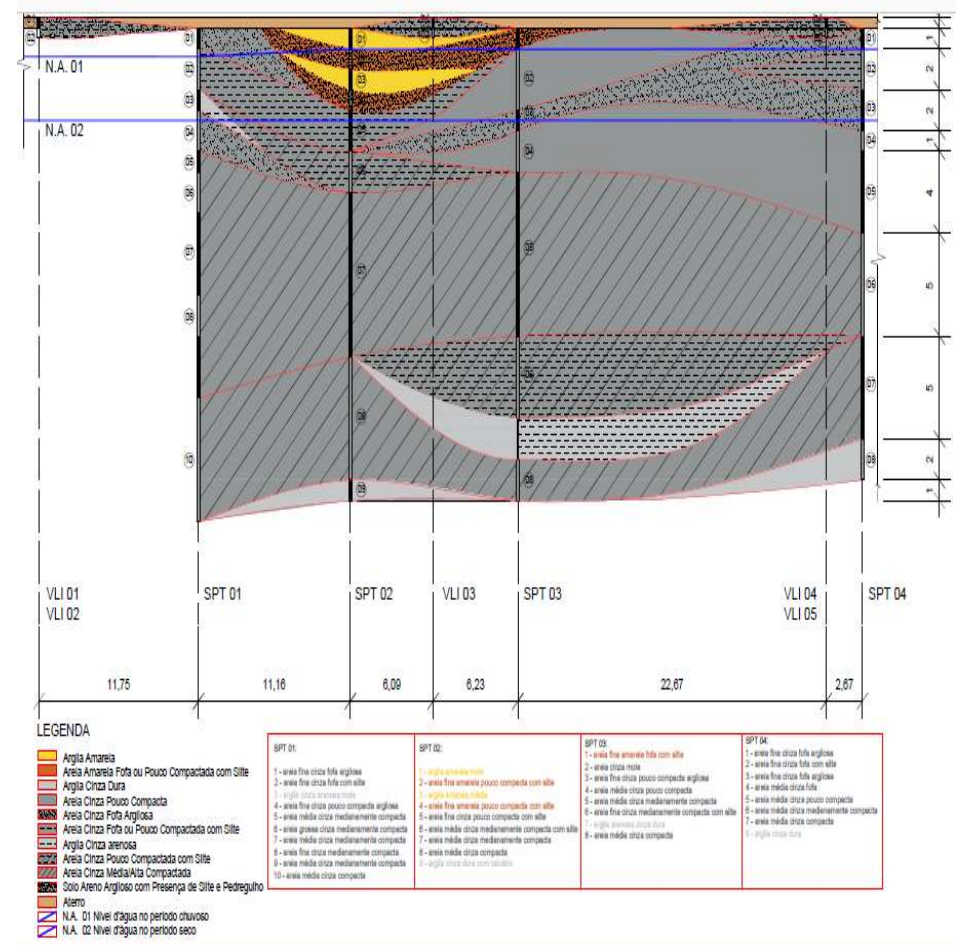

Figura 6: Corte esquemático do Solo.

Tabela 2: Percentuais da fração granulométrica.

\begin{tabular}{|c|c|c|c|c|c|}
\hline \multicolumn{2}{|c|}{ Amostra } & \multicolumn{4}{|c|}{ Fração Granulométrica (\%) } \\
\hline Ponto & Prof. (m) & Pedregulho & Areia & Silte & Argila \\
\hline 1.1 & 0,5 & 5 & 57 & 4 & 34 \\
\hline 1.2 & 1 & 2 & 55 & 4 & 39 \\
\hline 2.1 & 0,5 & 5 & 58 & 5 & 32 \\
\hline 2.2 & 1 & 1 & 58 & 10 & 31 \\
\hline 3.1 & 0,5 & 1 & 59 & 6 & 34 \\
\hline 3.2 & 1 & 4 & 52 & 4 & 40 \\
\hline 4.1 & 0,5 & 4 & 52 & 7 & 37 \\
\hline 4.2 & 1 & 5 & 55 & 3 & 37 \\
\hline 5.1 & 0,5 & 1 & 55 & 6 & 38 \\
\hline 5.2 & 1 & 11 & 55 & 6 & 38 \\
\hline
\end{tabular}

Tabela 3: Índices de Consistência e sistema unificado de Classificação do Solo.

\begin{tabular}{|c|c|c|c|c|c|c|}
\hline \multicolumn{2}{|c|}{ Amostra } & \multicolumn{3}{|c|}{$\begin{array}{l}\text { Limites de Consistência dos Solos } \\
(\%)\end{array}$} & \multicolumn{2}{|c|}{ Sistema de Classificação do Solo } \\
\hline $\begin{array}{l}\text { Pont } \\
0\end{array}$ & $\begin{array}{l}\text { Prof. } \\
(\mathrm{m})\end{array}$ & LL (\%) & LP (\%) & IP (\%) & $\begin{array}{l}\text { Peso específico dos grãos } \\
\left(\mathrm{g} / \mathrm{m}^{3}\right)\end{array}$ & $\begin{array}{l}\text { Sistema Unificado de Classificação dos Solos } \\
\text { (SUCS) }\end{array}$ \\
\hline \multirow[t]{2}{*}{1} & 0,5 & 33,04 & 19,9 & 13,14 & 2,638 & SC ( AREIA COM ARGILA) \\
\hline & 1 & 33,15 & 19,71 & 13,44 & 2,638 & SC ( AREIA COM ARGILA) \\
\hline \multirow[t]{2}{*}{2} & 0,5 & 35,02 & 20,86 & 14,16 & 2,634 & SC ( AREIA COM ARGILA) \\
\hline & 1 & 26,97 & 17,15 & 9,82 & 2,645 & SC ( AREIA COM ARGILA) \\
\hline \multirow[t]{2}{*}{3} & 0,5 & 28,73 & 18,06 & 10,67 & 2,624 & SC ( AREIA COM ARGILA) \\
\hline & 1 & 34,62 & 20,48 & 14,14 & 2,634 & SC ( AREIA COM ARGILA) \\
\hline \multirow[t]{2}{*}{4} & 0,5 & 36,17 & 21,7 & 14,47 & 2,634 & SC ( AREIA COM ARGILA) \\
\hline & 1 & 33,2 & 20,92 & 12,28 & 2,641 & SC ( AREIA COM ARGILA) \\
\hline \multirow[t]{2}{*}{5} & 0,5 & 34,21 & 20,53 & 13,68 & 2,641 & SC ( AREIA COM ARGILA) \\
\hline & 1 & 33,82 & 20,62 & 13,2 & 2,641 & SC ( AREIA COM ARGILA) \\
\hline
\end{tabular}

As 10 amostras de solos foram classificadas como um solo SC (Areia-Argila) segundo a classificação do sistema unificado de Solos (SUCS), como também foram realizados os ensaios de caracterização física do solo, conforme tabela 3. O Solo estudado possui um percentual elevado de fração arenosa com predominância de fração maior de areia fina e também uma fração considerável de argila, dando ao solo um comportamento plástico típico de solos argilosos. 


\section{Ensaio de permeabilidade carga variável In Situ}

Dentre as variáveis que influenciam o fluxo de água no solo, e assim, a recarga, bem como o transporte de poluentes, a condutividade hidráulica (K) ou coeficiente de permeabilidade se destaca (FITTS, 2002). Os ensaios (Figura 7) foram realizados na camada de aterro, perfazendo um total de 6 ensaios permeabilidade sendo 3 ensaios com água e 3 ensaios com esgoto tratado do sistema antigo das edificações em funcionamento do IFPE, conforme orienta a NBR1369/1997, o mínimo de 3 ensaios para projetos de sumidouros, valas de infiltração ou filtração.

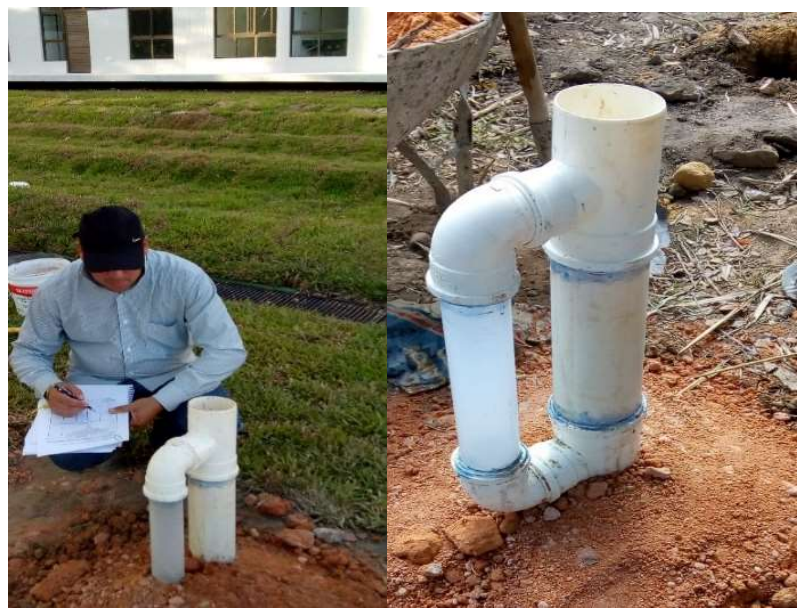

Figura 7: Ensaio de permeabilidade com carga variável.

Os Resultados do coeficiente de Permeabilidade ou coeficiente hidráulico realizados na área da vala de infiltração são apresentados na tabela 4.

Tabela 4: Valores da Permeabilidade (K) in situ..

\begin{tabular}{|c|c|c|}
\hline \multicolumn{3}{|l|}{ PERMEABILIDADE } \\
\hline LOCAÇÃO & $\mathrm{K}(\mathrm{cm} / \mathrm{s})$ & PERCOLANTE \\
\hline FURO 1 & 3,09E-05 & Água (H2O) \\
\hline FURO 2 & $2,08 \mathrm{E}-05$ & Água (H2O) \\
\hline FURO 3 & $2,89 \mathrm{E}-05$ & Água (H2O) \\
\hline Média aritmética & $2,69 \mathrm{E}-05$ & Água (H2O) \\
\hline FURO 1 & $2,32 \mathrm{E}-06$ & Esgoto doméstico Tratado \\
\hline FURO 2 & $1,78 \mathrm{E}-06$ & Esgoto doméstico Tratado \\
\hline FURO 3 & $1,89 \mathrm{E}-06$ & Esgoto doméstico Tratado \\
\hline Média aritmética & $2,00 \mathrm{E}-06$ & Esgoto doméstico Tratado \\
\hline
\end{tabular}

Ao analisar os resultados de permeabilidade in situ dos percolantes, observou-se uma variação em torno de 10 vezes entre o fluído água (H2O) e o esgoto tratado, corroborando com os estudos (BETIM, 2013), ou seja, os valores de $K$, ao longo do tempo, tendem à uniformização, em função do fechamento dos poros e pelo material em suspensão contido nos lixiviados (esgoto tratado). Ressalta-se que as permeabilidade de 10-5 e 10-6 são típicos de solos com baixa permeabilidade, diminuindo a velocidade de propagação da pluma contaminante em direção ao lençol freático.

\section{Esgoto doméstico: sistema de tratamento}

No Brasil, são empregadas várias técnicas de tratamento de esgotos, desde sofisticados sistemas até processos simples. Entre as tecnologias de baixo custo e pequenas vazões desenvolvidas nos últimos vinte 
anos, destacam-se: reatores anaeróbios de fluxo ascendente por meio de lodo, tanques sépticos seguidos de filtros anaeróbios e formas de disposição controlada no solo, sumidouros, valas de infiltração ou filtração (ÁVILA, 2005).

Os esgotos domésticos são constituídos aproximadamente de $99,9 \%$ de líquido e o restante 0,1\% de material sólido, contém basicamente matéria orgânica e mineral (em solução e suspensão), assim como alta quantidade de bactérias e outros organismos patogênicos e não patogênicos (SPERLING, 2014). No presente estudo, o sistema individualizado de tratamento de esgoto doméstico, a vala de infiltração torna-se o último estágio do Processo do tratamento para o fluído (Esgoto tratado) a ser percolado pelo meio poroso. A coleta da amostra simples do Esgoto foi obtida na caixa de inspeção da vala de infiltração do sistema existente da unidade Educacional que tem operação em torno de 30 anos, conforme coordenadas UTM da tabela 5. A amostra do Esgoto doméstico piloto tratado foi analisada, no laboratório de físico-química, microbiologia e tecnologia ambiental do ITEP conforme os parâmetros e resultados apresentados na tabela 6 .

Tabela 5: Coordenada Universal Transversa Mercator (UTM) da caixa de inspeção.

\begin{tabular}{|l|l|l|l|l|}
\hline LOCAL & \multicolumn{1}{|l|}{ COORDENADAS UTM } & \multicolumn{2}{l|}{ FUSO } & ZONA \\
\hline \multirow{2}{*}{ CAIXA DE INSPEÇÃO } & NORTE (metros) & ESTE (metros) & & \\
\cline { 2 - 5 } & 9.108 .576 & 285.139 & 25 & L \\
\hline
\end{tabular}

Tabela 6: Resultados dos Parâmetros do Esgoto Tratado.

\begin{tabular}{|l|l|l|l|}
\hline Parâmetros & Resultados & Unidade & Método \\
\hline Demanda Química de Oxigênio & 75,9 & $\mathrm{mg} \mathrm{O} / \mathrm{L}$ & SMEWW 5220 C \\
\hline Demanda Bioquímica de Oxigênio & 2 & $\mathrm{mg} \mathrm{O} / \mathrm{L}$ & SMEWW 5210 B \\
\hline Nitrato $\left(\mathrm{NO}_{3}\right)$ & $\mathbf{5 5 , 2}$ & $\mathrm{mg} / \mathrm{L}$ & SMEWW 4500 B \\
\hline Nitrito $\left(\mathrm{NO}_{2}\right)$ & $\mathbf{1 2 , 8}$ & $\mathrm{mg} / \mathrm{L}$ & SMEWW 4500 B \\
\hline Amônia ( $\left.\mathbf{N H}_{3}\right)$ & 14,6 & $\mathrm{mg} / \mathrm{L}$ & SMEWW 4500 F \\
\hline Coliformes Totais & 2 & $\mathrm{NMP} / 100 \mathrm{~mL}$ & APHA -EPA \\
\hline Coliformes Termotolerantes & 2 & $\mathrm{NMP} / 100 \mathrm{~mL}$ & APHA -EPA \\
\hline
\end{tabular}

NMP: Número mais provável. Fonte: ITEP (2018).

Após análise dos Parâmetros apresentados na Tabela 06, identifica-se que a amostra do esgoto tratado tem valores do Nitrato/ Nitrito acima da tolerância das 3 (Três) classes de água doce presentes na Resolução no 357/2005 do CONAMA, ou seja, a infiltração deste fluido no meio poroso acarretará contaminação.

Afim de diminuir as concentrações de Nitratos e Nitritos no meio, existe algumas soluções desde do sistemas radicular dos vegetais como também um pós-tratamento com Barreiras reativas de carvão ativado.

O processo de redução do nitrato a nitrito e este a amônia, gás nitrogênio ou oxido nítrico é chamado desnitrificação e ocorre em solos saturados com água ou realizado pelas bactérias do gênero Pseudomonas que podem ser usadas para retirar nitrato e nitrito da água (MEURER, 2004). A maioria das plantas absorvem nitrato, uma exceção é o arroz (Oryza sativa, L.) que devido ao seu sistema de produção sob lamina de água se adaptou a absorver amônio (MEURER, 2004). Logo a utilização de vegetação específicas se faz interessante para a purificação da água servida e consequentemente diminuição da concentração de Nitrato no meio poroso saturado.

Segundo Lins (2011), em estudos realizado no Aterro da Muribeca, Jaboatão dos Guararapes/PE, para tratamento do Lixiviado, utilizou-se vários métodos de tratamento em escala piloto a fim de diminuir a carga 
contaminante deste lixiviado. O mesmo autor ainda afirma que uma das propostas é o tratamento do lixiviado por barreiras reativas com carvão ativado, ou seja, nos estudos realizados, as amostras de amônia (NH3) e a demanda química de oxigênio (DQO) tiveram reduções médias após o tratamento 40,6 \% e 50,5\%, respectivamente, conforme a Figura 8.

\begin{tabular}{|c|c|c|c|c|}
\hline Amostra: & $\begin{array}{c}\text { Precipitação } \\
\text { Quimica }\end{array}$ & $\begin{array}{c}\text { Stripping da } \\
\text { Amônia }\end{array}$ & Correção de pH & Barreira Reativa \\
\hline Amônia & Mín. 3,9\% & Mín. 9,8\% & Mín. 2\% & Mín. 21,2\% \\
& Méd. 13,5\% & Méd. 12,6\% & Méd. 6,2\% & Méd. 40,6\% \\
& Máx. 20,5\% & Máx. 15,1\% & Máx. 9,5\% & Máx. 56\% \\
\hline Condutividade & Mín. -54,4\% & Mín. 0,1\% & Mín. 19\% & Mín. - 8,8\% \\
& Med.-48,3\% & Méd. 6,6\% & Méd. 28\% & Méd. 8,8\% \\
& Máx. -44,9\% & Máx. 14,1\% & Máx. 35\% & Máx. 31\% \\
\hline Turbidez & Mín. 68,1\% & Mín.-43,3\% & Mín. -43,3\% & Mín. 15,5\% \\
& Med. 79,6\% & Méd. - 8,8\% & Méd. -13,5\% & Méd. 33\% \\
& Máx. 88,8\% & Máx. 22,6\% & Máx. 9,7\% & Máx. 64,7\% \\
\hline DQ0 & Mín. 27,6\% & Mín. 3,5\% & Mín. 23,7\% & Mín. 18,9\% \\
& Med. 45,7\% & Méd. 8,6\% & Méd. 30\% & Méd. 50,5\% \\
& Máx. 58,2\% & Máx. 16\% & Máx. 34,3\% & Máx. 63,9\% \\
\hline Cor & Mín. 74,6\% & Mín. 3,9\% & Mín. 6,9\% & Mín. 41,5\% \\
& Med. 85\% & Méd. 8,8\% & Méd. 30,3\% & Méd. 59,4\% \\
& Max. 97,9\% & Máx. 13,1\% & Máx. 68,5\% & Máx. 81,2\% \\
\hline
\end{tabular}

Figura 8: Desempenho Mínimo, Médio e Máximo das unidades de Tratamentos. Fonte: Lins (2011).

Logo a utilização de vegetações típicas de cada região para contribuir com a absorção do Nitrato (NO3) /Amônia (NH3) no meio poroso como também um pós tratamento do carvão ativado é de extrema importância para diminuir as cargas contaminantes por Nitratos, Nitritos e amônia oriundas do esgoto doméstico.

\section{Velocidade linear média do Fluido}

Denomina-se de Advecção o transporte de contaminantes devido ao processo de fluxo de água no solo. Com o deslocamento da água, os solutos presentes na mesma se movimentam com uma velocidade que é igual à velocidade média da água e sem alterar sua concentração na solução (THOMÉ et al., 2018). Advecção é um dos principais mecanismos de transporte de contaminante no meio poroso. Nas amostras dos 3 furos de sondagem a trado e baseado na condutividade hidráulica dos ensaios in situ com esgoto tratado consegue-se determinar a velocidade média linear do meio (Tabela 07).

Tabela 7: Velocidade média linear de alcance da pluma Contaminante

\begin{tabular}{|l|l|l|l|}
\hline Velocidade linear média cm/ano & Furo 1 & Furo 2 & Furo 3 \\
\hline $\mathbf{1 9})$ Ano & 5,34 & 1,86 & 2,3 \\
\hline $\mathbf{2 9})$ Ano & 10,68 & 3,73 & 4,61 \\
\hline $\mathbf{3 9}$ ) Ano & 16,02 & 5,59 & 6,91 \\
\hline $\mathbf{4 9}$ ) Ano & 21,37 & 7,45 & 9,22 \\
\hline $\mathbf{5 9}$ ) Ano & 26,71 & 9,31 & 11,52 \\
\hline $\mathbf{6 9})$ Ano & 32,05 & 11,18 & 13,83 \\
\hline $\mathbf{7 9})$ Ano & 37,39 & 13,04 & 16,13 \\
\hline $\mathbf{8 9})$ Ano & 42,73 & 14,9 & 18,43 \\
\hline $\mathbf{9 9})$ Ano & 48,07 & 16,76 & 20,74 \\
\hline $\mathbf{1 0}$ ) Ano & $\mathbf{5 3 , 4 2}$ & 18,63 & 23,04 \\
\hline
\end{tabular}


Os cálculos da velocidade média linear de alcance descritos na tabela 9, plota-se um gráfico (Figura 10) a fim de observar ao longo tempo (ano) o alcance da pluma contaminante levando em consideração o processo de Advecção. Ressalta-se que a estimativa de alcance da pluma de contaminação do Esgoto Tratado, no caso os Nitratos, Nitritos, Amônia, é $53,42 \mathrm{~cm}$ no 10 을 ano conforme descrito no Furo 1 . Sobre o alcance da pluma de contaminação ter atingindo $53,42 \mathrm{~cm}$, a condutividade hidráulica é um dos poucos parâmetros físicos que variam tanto quanto a permeabilidade exibindo variação de até 12 ordens de grandeza para a (BETIM, 2013).

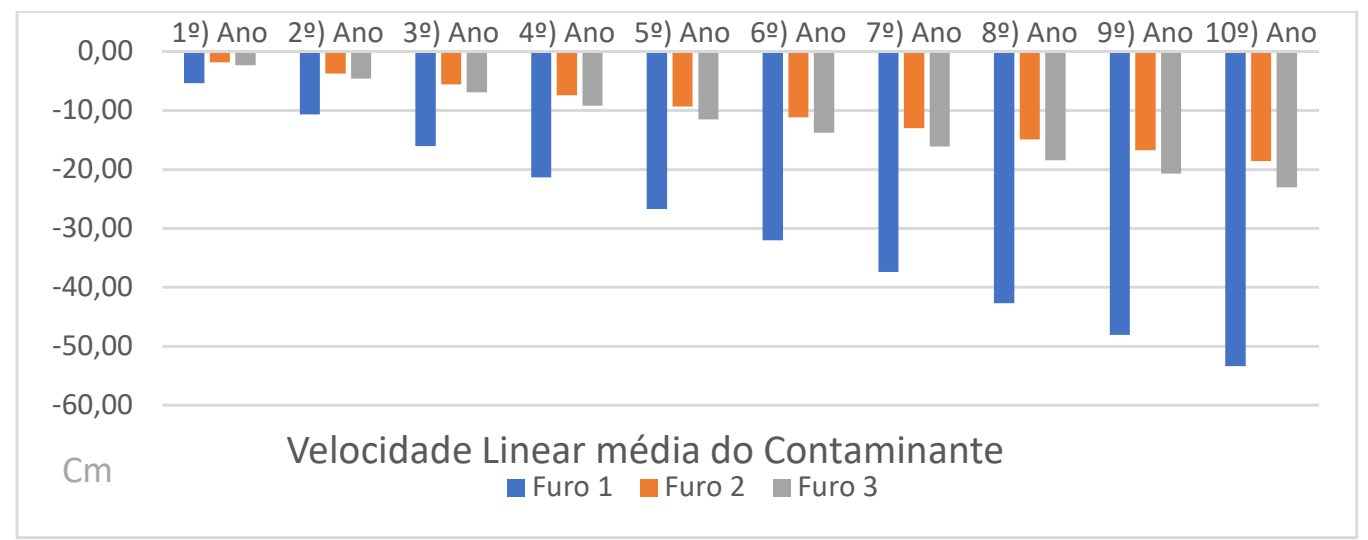

Figura 9: Velocidade média linear $x$ tempo.

Como o nível hidrostático do Lençol freático encontra-se a 3,00 metros no período chuvoso e na estação seca a um nível de 5,00 metros de profundidade, atenua-se a contaminação pelo esgoto tratado ao lençol freático, devido a pluma não ter alcançado estas profundidades no período estimado de 1 a 10 anos, ou seja, a velocidade propagação é baixa devido as características da permeabilidade e do solo. Devido à baixa Condutividade hidráulica do contaminante pelo meio poroso através do transporte advectivo como as características intrínsecas do solo Areia-argila.

\section{Matriz-PEIR}

A Matriz-PEIR, acrescenta a variável Impacto sendo utilizada para orientar na avaliação do estado do Meio Ambiente e o que pode ser feito para mitigar ou evitar os problemas atuais e futuros. A matriz é classificada em quatro indicadores principais: pressão, estado, impacto e resposta (LINS, et al, 2018). Os Modelos PEIR e FPEIR incluem o Impacto (I), que são os indicadores que medem as consequências da degradação ambiental sobre o homem e em seu entorno.

De posse de todas as informações foi possível montar a Matriz PEIR para análise do comportamento e possíveis impactos ambientais gerados pelos efluentes líquidos (Quadro 2). Procurar compreender a causa e efeito das ações antrópicas sobre o meio ambiente é fundamental para tomada de decisões que contribuirá na orientação do diagnóstico ambiental e o que pode ser feito para prevenir e mitigar os impactos negativos atuais e futuros. 
Quadro 2: Matriz PEIR para percolação de esgoto tratado em vala de infiltração.

\begin{tabular}{|c|c|c|c|}
\hline PRESSÃO & ESTADO & IMPACTO & RESPOSTA \\
\hline $\begin{array}{l}\text { Valores acima dos } \\
\text { Parâmetros da normativa do } \\
\text { Conama }\end{array}$ & $\begin{array}{l}\text { Percolação de } \\
\text { efluentes líquidos }\end{array}$ & $\begin{array}{l}\text { > Contaminação dos corpos } \\
\text { hídricos superficiais e } \\
\text { subterrâneos; } \\
\text { > Contaminação do solo; } \\
\text { > Disseminação de doenças; }\end{array}$ & $\begin{array}{l}\text { > Solo com baixa permeabilidade } \\
\text { (impermeável); } \\
\text { > Tratamento do efluentes pelo } \\
\text { sistema Radicular da vegetação; } \\
\text { > Pós-tratamento com Carvão ativado } \\
\text { (Proposta) } \\
\text { > Velocidade média de Percolação } \\
\text { (Advecção) do Contaminante Baixa. }\end{array}$ \\
\hline
\end{tabular}

Fonte: Adaptado de Lins et al. (2018).

Ao analisar a matriz PEIR percebe-se que existe o risco de impacto ambiental alto, no entanto as características apresentadas pelo o Solo estudado como a baixa permeabilidade, a própria vegetação aplicada no local, a baixa velocidade de percolação definem o comportamento do efluente líquido no meio.

\section{CONCLUSÕES}

A partir dos resultados obtidos é possivel concluir que os ensaios realizados na pesquisa na área da vala de infiltração do Centro de Pesquisa do IFPE apresentam: Os ensaios de Permeabilidade (K) in situ com água e com o esgoto doméstico que corroboraram com a classificação do Solo de aterro (areia-argila), com Condutividade hidráulica para a água de $2,69 \times 10^{-5}$ e para o esgoto de 1,99 × $10^{-6}$; A amostra piloto do esgoto demostra que as concentrações de Nitrato $\left(\mathrm{NO}_{3}\right) \operatorname{com} 55,20 \mathrm{mg} / \mathrm{L}$ e do Nitrito $\left(\mathrm{NO}_{2}\right) \mathrm{com} 12,80 \mathrm{mg} / \mathrm{L}$ estão acima da faixa da Resolução do CONAMA no 357, acarretando risco a contaminação do solo e do Lençol freático; O maior alcance da pluma de contaminação do Esgoto doméstico tratado é $53,43 \mathrm{~cm}$ de profundidade no período de 10 (dez) anos, não atigindo o nível freático e consequentemente não propagando a contaminação da pluma; Os estudos de desnitrificação confirmam a retirada do Nitrato do meio poroso pelas raízes das plantas e como a velocidade linear média é considerada baixa ao longo dos 10 (dez) anos, a própria vegetação assente na vala de infiltração através do seu sistema radicular pode se beneficiar do Nitrato que é reduzido a amônia no interior da célula vegetal e consumir-lo atenuando a carga de contaminação no solo; Com os parâmetros e estudos realizados constate-se que a carga de contaminação oriunda da amostra do Esgoto doméstico não atingir o nível do lençol freático, não gerando a propagação da contaminação. A utilização da própria vegetação com seu sistema radicular contribui para descrescer os níveis de Nitratos e Nitratos a patamares aceitáveis de acordo com a Resolução do Conama 357/05; A matriz PEIR demostra que existe a possibilidade do Impacto ambiental alto, mas as respostas do sistema demostram que as características do meio mitigam esta possível contaminação, propondo a utilização de carvão ativado no pós tratamento.

AGRADECIMENTOS: Ao Instituto de Tecnologia de Pernambuco (ITEP), pois este artigo é fruto da pesquisa do curso de mestrado profissional em Tecnologia Ambiental, bem como agradecer ao financiamento do Instituto Federal de Educação, Ciência e Tecnologia de Pernambuco (IFPE) para o desenvolvimento da pesquisa, bem como o Laboratório de Geotecnia da Universidade Federal de Pernambuco (UFPE) pelo apoio. 


\section{REFERÊNCIAS}

ABGE. Associação Brasileira de Geologia de Engenharia. Ensaio de Permeabilidade em Solo: Orientação para sua Execução no Campo. São Paulo: ABGE, 2013.

ABES. Associação Brasileira de Engenharia Sanitária e Ambiental. Aos 10 anos da Lei do Saneamento Básico, Brasil ainda apresenta condições lamentáveis. Rio de Janeiro: ABES, 2015.

ABNT. Associação Brasileira de Normas Técnicas. NBR 13133: Execução de levantamento topográfico. Rio de Janeiro: ABNT, 1996.

ABNT. Associação Brasileira de Normas Técnicas. NBR 13969: Tanques sépticos: Unidades de Tratamento Complementar e disposição Final dos efluentes líquidos: Projeto, construção e operação. Rio de Janeiro: ABNT, 1997.

ABNT. Associação Brasileira de Normas Técnicas. NBR 14545: Solo: Determinação do coeficiente de permeabilidade de solos argilosos a carga variável. Rio de Janeiro: ABNT, 2000.

ABNT. Associação Brasileira de Normas Técnicas. NBR 6484: Solo: Sondagens de simples reconhecimento com SPT: Método de ensaio. Rio de Janeiro: ABNT, 2001.

ABNT. Associação Brasileira de Normas Técnicas. NBR 7181: Solo: Análise Granulométrica. Rio de Janeiro: ABNT, 2016.

ABNT. Associação Brasileira de Normas Técnicas. NBR 9603 Sondagem a trado: Procedimento. Rio de janeiro: ABNT, 2015.

ÁVILA, R. O.. Avaliação do desempenho de sistemas tanque séptico-filtro anaeróbio com diferentes tipos de meio suporte. Dissertação (Mestrado em Engenharia Civil) Universidade Federal do Rio de Janeiro, Rio de Janeiro, 2005.

BETIM, L. S.. Caracterização da condutividade hidráulica dos solos e estudo da vulnerabilidade à contaminação dos aquíferos da sub-bacia do Córrego Palmital. Dissertação (Mestrado em Engenharia Ambiental) - Universidade Federal de Viçosa, Viçosa, 2013.

BRASIL. Resolução do CONAMA 357: Dispõe sobre a classificação dos corpos de água e diretrizes ambientais para o seu enquadramento, bem como estabelece as condições e padrões de lançamento de efluentes, e dá outras providências. Brasília: DOU, 2005.

FAO. Organização das Nações Unidas para a Alimentação e a Agricultura. Aumento da contaminação do solo ameaça segurança alimentar, dia Mundial do solo. 2018.

FITTS, C. R.. Groundwater Science. London: Academic Press, 2002.

FREITAS, G. S.; NEVES, T. C.. Estudo de solos bem graduados por meio do ensaio de compactação. Revista Educação, Guarulhos, v.12, n.2, p.50, 2017.
IFPE. Instituto Federal de Educação, Ciência e Tecnologia de Pernambuco. Projeto hidrossanitário. Recife: IFPE, 2017.

INMET. Instituto Nacional de Metereologia. Dados metereológicos da Série histórica de $\mathbf{1 0}$ anos de Precipitação mensal na Região Metropolitana do Recife, Estação 82900. Recife: INMET, 2017.

LINS, E. A. M.. Proposição e avaliação de um sistema experimental de processos físicos e químicos para tratamento de lixiviado. Tese (Doutorado em Engenharia Civil) - Universidade Federal de Pernambuco, Recife, 2011.

LINS, E. A. M.; LINS, A. S. B. M.; SOUZA, J. M.; MELO, D. C. P.; PAZ, D. H. F.. Uma análise ambiental dos impactos negativos gerados pelo cemitério de São Luís, Escada/PE. In: CONGRESSO SUL-AMERICANO DE RESÍDUOS SÓLIDOS E SUSTENTABILIDADE, 1. Anais. Gramado: CONRESOL, 2018.

MARCONI, M. A.; LAKATOS, E. M.. Técnicas de Pesquisa. 7 ed. São Paulo: Atlas, 2018.

MOURA, C. C.; GASTMANS, D.; KIANG, C. H.; MODESTO, R P.; RODRIGUES, P. F.; RUBY, E. C.; BORGES, A. V. Concentrações de nitrato nas águas subterrâneas em áreas rurais do município de São José do Rio Preto (SP). Águas Subterrâneas, v.3, n.29, p.268-284, 2015.

MARQUES, J. A. F.; VICTOR, J.. Estudo Comparativo do Coeficiente de Absorção dos Solos do Terciário de Maceió/AL, com os Valores Sugeridos por Norma. In: CONGRESSO BRASILEIRO DE MECÂNICA DOS SOLOS E ENGENHARIA GEOTÉCNICA, 15. Anais. Gramados, 2010

MEURER, E. J.. Fundamentos de Química do Solo. 2 ed. Porto Alegre: UFRGS, 2004

RESENDE A. V.. Agricultura e qualidade da água: contaminação da água por nitrato. Planaltina: EMBRAPA, 2004.

MOTA, F.; SPERLING, M. V. M.. Nutrientes de esgoto sanitário: utilização e remoção. Rio de Janeiro: ABES, 2009.

QUAGGIO, C. S.; GASTMANS, D.; KIRCHHEIM, R.; BATISTA, L. V.. Variações na composição das águas subterrâneas do Sistema Aquífero Serra Geral em território brasileiro e sua relação com anomalias hidrogeoquímicas. Águas Subterrâneas, v.32, n.3, p.283-294, 2018.

SPERLING, M. V.. Introdução à Qualidade das Águas e ao Tratamento de Esgotos: Coleção Princípios do Tratamento Biológico de Água. 4 ed. Belo Horizonte: UFMG ,2014.

THOMÉ, A.; KNOP, A.. Movimento de contaminantes no solo. Porto Alegre: UFRGS, 2018.

VARNIER, C.; HIRATA, R.; ARAVENA, R.. Examining nitrogen dynamics in the unsaturated zone under an inactive cesspit using chemical tracers and environmental isotopes. Applied Geochemistry, v.78, p.129-138, 2017.

A CBPC - Companhia Brasileira de Produção Científica (CNPJ: 11.221.422/0001-03) detém os direitos materiais desta publicação. Os direitos referem-se à publicação do trabalho em qualquer parte posteriormente ser publicados em coletâneas impressas sob coordenação da Sustenere Publishing da Companhia Brasileira de Produção Científica eseus parceiros autorizados. Os (as) autores (as) preservam os direitos autorais, mas não têm permissão para a publicação da contribuição em outro meio, impresso ou digital, em português ou em tradução. 